\title{
Isolation and purification of HLA-DR antigen from Daudi cell line by immunoaffinity chromatography
}

\author{
Zahra Khayyati ${ }^{1}$, Fatemeh Yari $^{1 *}$
}

1. Blood Transfusion Research Center, High Institute for Research and Education in Transfusion Medicine, Tehran, Iran

*Corresponding author:Tel: +98 2182052238 Fax: +98 2188601555

Address: IBTO bldg, Hemmat. Exp.Way. Next to the Milad Tower, Tehran, Iran, P.O. Box: 1449613111

E-mail: f.yari@ibto.ir

Received; 2016/09/3 revised; 2016/09/20 accepted; 2016/11/7

\section{Abstract}

Introduction: The major histocompatibility complex (MHC) is a group of cell surface proteins that are essential for recognizing foreign molecules in human and other mammals. The physiologic function of MHC molecules is the presentation of peptides to T cells. In this study, we evaluated the purification of a class II MHC molecule (HLA-DR) from a human Burkitt's lymphoma cell line; Daudi.

Materials and methods: We described a simple procedure for purifying human HLA molecules from the cells lysate. As a representative model, HLA-DR was purified from Daudi cell line. The cell membrane was solubilized by a buffer contained NP-40 detergent. Subsequently, the isolation of the membrane antigen was carried out by affinity chromatography method using mouse anti-human HLA-DR monoclonal antibody. The size and the specificity of the purified antigen were determined by Bradford and ELISA methods, respectively.

Results: The purified HLA antigen was obtained in approximately 20-30 micrograms in each run of chromatography. Additionally, ELISA method demonstrated the HLA-DR specificity of the purified protein.

Conclusion: The results indicated that affinity purification of HLA-DR antigen by means of specific monoclonal antibody is a simple and fast procedure for obtaining the purified antigen.

Keywords: HLA-DR, Affinity chromatography, ELISA

\section{Introduction}

Major histocompatibility complex (MHC) encodes protein molecules that are highly polymorphic surface glycoproteins. These molecules are involved in immune recognition (1). Most nucleated cells constitutively express MHC class I, whereas MHC class II is restricted to antigen presenting cells (APCs) such as dendritic cells, macrophages and $\mathrm{B}$ cells. The class I MHC molecule consists of two non-covalently associated chains; a 44,000 Da transmembrane $\alpha$ chain, and a 14,000 Da $\beta_{2}$-microglobulin component. The gene products of the class I locus are HLA-A, $\mathrm{B}$, and $-\mathrm{C}$. The class II MHC molecule has two non-covalently associated transmembrane chains; $\alpha$ chain of 34,000 $\mathrm{Da}$ and $\beta$ chain of $29,000 \mathrm{Da}$ (2). The gene products of the class II locus are HLA-D. Both class I and class II MHC proteins are strongly associated with a broad spectrum of peptides which are presented to T cell, via interaction with the $\mathrm{T}$ cell receptor $(1,3)$. Of the three allelic HLA-D forms HLA-DR, HLA-DP, and HLA-DQ, the major product is HLA-DR. The HLA-DR region of the MHC localizes in the short arm of the chromosome 6 and its importance in immunological reactions has been demonstrated (4-7). The most 
commonly used procedure for purification of MHC molecules is based on affinity chromatography originally developed by Parham (1976) and Gorga et al. (1). Affinity chromatography, a highly selective separation technique, is a type of adsorption chromatography where the target molecule is reversibly adsorbed by a ligand immobilized on an insoluble support. The ligand is selected with respect to its affinity for a biomolecule, such as the affinity of an antibody to its antigen or that of an antigen to its antibody (8-10). Here an optimized affinity chromatography protocol was used to isolate and purify the HLA-DR antigen from the membrane of an immortalized B cell line. This cell line doesn't express HLA class I molecules. The cell lysate was prepared and an affinity chromatography was established.

\section{Materials and methods}

Daudi Cell line :Human Burkitt's lymphoma cell line; Daudi was purchased from National Cell Bank of Iran in Pasteur Institute. Cells were grown in RPMI 1640 (Gibco, Germany) supplemented with 10\% fetal bovine serum (FBS) (Gibco, Germany), $1.0 \%$ L-glutamine (Merck, Germany), $100 \mathrm{U} / \mathrm{ml}$ penicillin (Sigma, USA) and $100 \mu \mathrm{g} / \mathrm{ml}$ streptomycin (Sigma, USA). Cells were pelleted, washed with phosphate-buffered saline (PBS) and kept frozen at $-70^{\circ} \mathrm{C}$ until the solubilization of lipid bilayers.

Solubilization of the cell membrane proteins :For the preparation of the solubilized cell membrane antigens, cells were suspended in $1 \mathrm{ml}$ lysis buffer containing; $25 \mathrm{mM}$ Tris-HCL (Merck, Germany), $150 \mathrm{mM}$ NaCL, $10 \mathrm{mM}$ EDTA, $1.0 \%$ NP-40, $\mathrm{pH} 7.5$ and $1 \mathrm{mM}$ phenylmethylsulfonyl fluoride (PMSF; Sigma, USA) with vigorous vortexing. To remove insoluble cellular debris, the lysate was centrifuged at $1000 \mathrm{~g}$ for $10 \mathrm{~min}$. The supernatant was collected and dialyzed against three changes of PBS buffer over 24 hours.

Immobilization of antibody on cyanogen bromide-activated Sepharose 4B: The monoclonal antibody mouse anti-human HLA-DR (Origene Technologies, USA) was coupled to $\mathrm{CNBr}$-activated Sepharose 4B (Sigma, USA), according to the manufacturer's instructions

Purification by affinity chromatography column: The supernatant of the cell lysate was passed through the HLA-DR affinity column, which was equilibrated with PBS. The HLA-DR antigen was eluted from the column by the elution buffer $(0.2 \mathrm{M}$ glycine, $\mathrm{pH} 2.8$ ). The eluted protein was immediately neutralized with $2 \mathrm{M}$ Trisbuffer $\mathrm{pH}$ 8.0. Protein fractions were collected and evaluated for the protein existence by reading the absorption at 280 $\mathrm{nm}$. After condensing the eluted protein, the protein concentration was measured by Bradford method using different concentrations of bovine serum albumin (BSA) (Merck, Germany) as the standard protein.

The specificity of the purified antigen: The specificity of HLA-DR antigen was determined by enzyme-linked immunosorbent assay (ELISA) method. Fifty microliters of the purified antigen $(5 \mu \mathrm{g} / \mathrm{ml})$ was coated in the wells of a polystyrene microtiter plate (Nunc, Denmark) at $4^{\circ} \mathrm{C}$ for overnight. The wells were blocked with $2 \%$ BSA for 3 hours at room temperature. Mouse anti-human HLA-DR antibody was added and the wells were incubated for 1 hour at room temperature. Then peroxidase-conjugated anti-mouse IgG (Fc specific) antibody (Sigma-Aldrich) was added. Between each step the wells were washed three times with PBS contained $0.06 \%$ Tween 20 (Sigma, USA) to remove the unbound molecules. TMB substrate solution (Trinity Biotech, USA) was added. Finally, after addition of the stop solution, the absorption was read at $450 \mathrm{~nm}$. 


\section{Results}

The reaction of the purified antigen with HLA-DR-specific antibody was shown. On the other hand negative results were observed for the wells with phosphate buffer (PBS) or wells coated with human chorionic gonadotropin (HCG) as an unrelated antigen. The results demonstrated that the purified antigen was HLA-DR (Figure 1). ELISA results for 3 lots of HLA-DR molecules was shown in Figure 1.

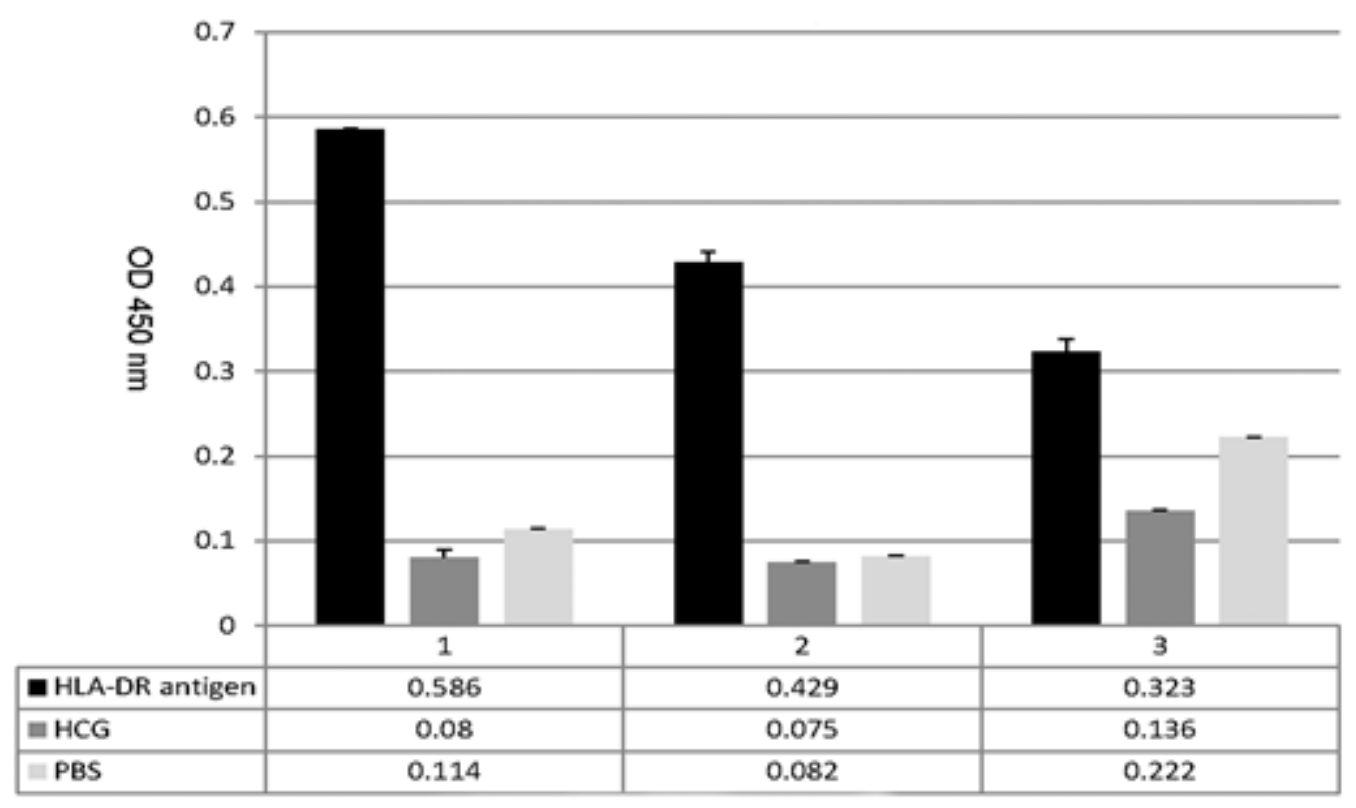

Figure 1. The specificity of the purified antigen was demonstrated using ELISA method. The reaction of the purified antigen with HLA-DR-specific antibody was shown. Negative results were obtained for PBS and HCG as an unrelated antigen. The results demonstrated that the purified antigen was HLA-DR. In this figure; 1, 2 and 3 refers to the optical densities of three lots of HLA-DR antigens obtained by affinity chromatography.

\section{Discussion}

Several protocols have been developed for the purification of different proteins. These protocols combine different protein purification techniques, such as ion exchange, gel filtration and affinity chromatography. Affinity chromatography by means of specific monoclonal antibodies can simplify the isolation of the protein of interest (11-14). The aim of this study was to purify HLA-DR antigen using affinity chromatography under the proper conditions that do not disturb the structural integrity of the protein. Daudi cell line was selected because it does not express HLA class I molecules but express
HLA class II antigens (15). The detergent NP-40 at the concentration of $1.0 \%$ was not toxic to the target cells $(16,17)$. The procedure described here can be suitable for obtaining HLA antigens from each cell type. Finally, purified HLA-DR antigen was characterized by ELISA method using monoclonal antibody specific for HLADR. Our study was correlated with Andrews and co-workers that used immunoaffinity chromatography to purify HLA-DR antigens. Although, they analyzed the purity of the protein using SDS-PAGE, they didn't analyze the specificity of the purified protein. We 
developed a simple and fast procedure to obtain a pure preparation of membrane proteins from each cell line. The simplicity of this method with minimal amount of the antibodies makes this method valuable. The purified protein can be used as an immunogen or any immunologic studies.

\section{References}

1. Malik P, Strominger JL. Perfusion chromatography for very rapid purification of class I and II MHC proteins. J Immunol Methods. 2000; 234(1-2):83-8.

2. Lazaro A, Tu B, Yang R, Xiao Y, Kariyawasam $\mathrm{K}, \mathrm{Ng}$ J, et al. Human leukocyte antigen (HLA) typing by DNA sequencing. Methods Mol Biol. 2013; 1034:161-95.

3. Jaimes Y, Seltsam A, Eiz-Vesper B, Blasczyk R, Figueiredo C. Regulation of HLA class II expression prevents allogeneic T-cell responses. Tissue Antigens. 2011; 77(1):36-44.

4. Bernard D, Maurizis JC, Chollet P, Chassagne J, Plagne R. Isolation and purification of HLA-DR antigens from tumour cells by affinity chromatography and chromatofocusing. J Chromatogr. 1984; 308:322-8.

5. Sachs JA, Kuo MC, Johnson AH, Nagatsuji T, DeMars R, Chang C, et al. The detection of HLA-DR, MB and MT determinants on purified class II molecules by inhibition of microcytotoxicity. J Immunol Methods. 1984; 73(2):387-99.

6. Kvist S, Wiman $\mathrm{K}$, Claesson L, Peterson PA, Dobberstein B. Membrane insertion and oligomeric assembly of HLA-DR histocompatibility antigens. Cell. 1982; 29(1):61-9.

7. Papadimitriou L, Zerva I, Georgouli M, Makatounakis T, Papamatheakis J, Athanassakis I. DO alpha(-)beta(+) expression in favor of HLA-DR engagement in exosomes.

\section{Acknowledgment}

This article is the result of a master's thesis on Transfusion Medicine in Blood Transfusion Research Center, High Institute for Research and Education in Transfusion Medicine, Tehran.

Immunobiology. 2013; 218(8):101925.

8. Sheng S, Kong F. Separation of antigens and antibodies by immunoaffinity chromatography. Pharm Biol. 2012;50(8):1038-44.

9. Andrews DW, Bono MR, Kaufman JF, Knudsen P, Strominger JL. Use of monoclonal antibody immunoaffinity columns to purify subsets of human HLA-DR antigens. Methods Enzymol. 1984; 108:600-6.

10. Thompson NE, Foley KM, Stalder ES, Burgess RR. Identification, production, and use of polyol-responsive monoclonal antibodies for immunoaffinity chromatography. Methods Enzymol. 2009; 463:475-94.

11. Perez L, Zulueta O, Melchor A, Hernandez L, Lopez R, Cazanave J, et al. Purification of human prostaticspecific antigen (hPSA) from seminal plasma by immunoaffinity chromatography using a monoclonal antibody anti total PSA. Hybridoma (2005). 2011; 30(3):247-51.

12. Dawson JR. The solubilization of HLA antigens with detergents and partial characterization of the antigendetergent complexes. Immunochemistry. 1976; 13(8):671-9.

13. Parham P. Monoclonal antibodies against HLA products and their use in immunoaffinity purification. Methods Enzymol. 1983; 92:110-38.

14. Brgles M, Sviben D, Forcic D, Halassy B. Nonspecific native elution of proteins and mumps virus in immunoaffinity chromatography. J chromatogr A. 2016; 1447:107-14. 
15. Millo E, Pietra G, Armirotti A, Vacca $\mathrm{P}$, Mingari MC, Moretta $\mathrm{L}$, et al. Purification and HPLC-MS analysis of a naturally processed HCMV-derived peptide isolated from the HEK293T/HLA-E+/U140+ cell transfectants and presented at the cell surface in the context of HLA-E. J Immunol Methods. 2007; 322(1-2):128-36.

16. Bernier I, Dautigny A, Colombani J, Jolles P. Detergent-solubilized HL-A antigens from human platelets: a comparative study of various purification techniques. Biochim Biophys Acta. 1974; 356(1):82-90.

17. Dautigny A, Bernier I, Colombani J, Jolles P. Purification and characterization of HL-A antigens from human platelets, solubilized by the non-ionic detergent NP-40. Biochim Biophys Acta. 1973; 298(4):783-9. 